\title{
Structural stability and local electronic properties of some EC synthesized magnetite nanopowders
}

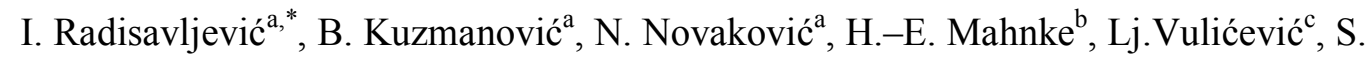
Kurko $^{\mathrm{a}}$, N. Ivanović ${ }^{\mathrm{a}}$

${ }^{a}$ University of Belgrade-Vinča Institute of Nuclear Sciences, P.O. Box 522, 11001

Belgrade, Serbia

${ }^{b}$ Helmholtz-Zentrum Berlin für Materialien und Energie GmbH, D-14109 Berlin, Germany

${ }^{c}$ Technical Faculty Čačak, University of Kragujevac, Svetog Save 65, 32000 Čačak, Serbia

Corresponding author: Tel.: +381 113408 254; Fax: +381 113440100 .

E-mail address: iva@vin.bg.ac.rs (I. Radisavljević)

\begin{abstract}
Structural and electronic properties, oxidation and aging effect of electrochemically (EC) synthesized magnetite nanopowders (NPs) are studied by means of X-ray diffraction (XRD), X-ray absorption fine structure (XAFS) and X-ray magnetic circular dichroism (XMCD). The obtained results enabled to get a direct insight into the structure and electronic properties of Fe immediate surrounding and to elucidate the influence of preparation conditions on stoichiometry of NPs and their stability in
\end{abstract}


ambient conditions. All investigated NPs are produced as non-stoichiometric $\mathrm{Fe}_{3-\delta} \mathrm{O}_{4}$ oxide phases, with the lattice constant and the $\mathrm{Fe}^{2+} / \mathrm{Fe}^{3+}$ ratio both in-between the values for bulk maghemite and magnetite. NPs synthesized under smaller current density $\left(\mathrm{J}=200 \mathrm{~mA} / \mathrm{dm}^{2}\right)$ are more magnetite-alike, whereas larger current density $\left(\mathrm{J}=1000 \mathrm{~mA} / \mathrm{dm}^{2}\right)$ has led to formation of NPs closer to maghemite. Oxidation of magnetite-like NPs is slower, although in the course of time particles agglomerate and oxide penetrates into the core. Maghemite-like NPs oxidize much faster and the oxide layer which is confined close to the particles' surface protects the core from further oxidation. In all NPs the fist coordination around Fe is pretty stable against both temperature and oxidation process. The temperature change from $293 \mathrm{~K}$ to $20 \mathrm{~K}$ considerably affects the second coordination around Fe, which is most likely a consequence of the Verwey transition present in all investigated samples.

Keywords: oxides; nanostructures; chemical synthesis; electronic structure; XAFS

\section{Introduction}

Iron oxides (in particular magnetite) are among the most investigated materials in human history. They are crucial for understanding the Earth's crust formation [1] and evolution of its magnetic field [2]. The first evidence of water on Mars is based on infra-red spectra of iron oxides found on its surface [3]. Iron oxides color pigments had been used in indigenous art since the pre-historic times [4]. The suppression of the rusting process as one of the major technological challenges would be impossible without detailed knowledge of the iron oxides and hydroxides structures and 
transformations [5]. Nowadays iron oxide nanoparticles (NPs) are indispensable in solving environmental issues like water purification and industrial wastewater treatment [6-10], in confronting global energy demands (fuel and heavy oil production, ...) [11] and in energy storage application (lithium ion batteries, supercapacitors, ...) [12-15]. Biocompatibility of magnetite $\left(\mathrm{Fe}_{3} \mathrm{O}_{4}\right)$ and maghemite $\left(\gamma-\mathrm{Fe}_{2} \mathrm{O}_{3}\right)[16]$ is vastly exploited in biology and medicine (biosensors, drug delivery, magnetic resonance imaging, hyperthermia, ...) [17-19]. High-technology applications such as data recording and storage [20,21], advanced optoelectronics [22] and spintronics [15,23,24] also benefit from the striking magnetic properties of magnetite NPs $[25,26]$. Functionality of iron oxide NPs is primarily determined by the particles composition, size and shape distribution and degree of structural order both in the bulk and at the surface. To control these properties numerous synthesis routes have been developed [27,28].

Electrochemical (EC) synthesis of magnetite NPs [29-32] enables control of the final product characteristics via adjustment of the parameters in the electrolytic cell. For instance, the mean size of the EC produced magnetite NPs can be settled inbetween 20 and $30 \mathrm{~nm}$, which makes them particularly attractive for biomedical applications [33].

Nominally claimed magnetite NPs are often (and to various extents) composed of nonstoichiometric oxide phases [34], and their instability in air ultimately causes oxidation to maghemite [35]. The oxidization rate of magnetite NPs in ambient conditions is sizedependent and can range from several months for $\mathrm{NPs}<10 \mathrm{~nm}$, up to several years for NPs $\sim 100 \mathrm{~nm}$ [36 and Refs. therein]. However, there is no general consensus regarding 
the complex oxidation mechanism, which presumably proceeds through a continual set of intermediate phases accompanied by cations and vacancies $(\mathrm{C}-\mathrm{V})$ reordering $[35,37]$.

Magnetite and maghemite both crystallize in the face-centered cubic (fcc) spinel structure, whose unit cell is composed of $32 \mathrm{O}^{2-}$ ions placed at the $32 \mathrm{e}$ crystallographic position, and $24 \mathrm{Fe}$ ions distributed over the 64 tetrahedral 8a (A) and 32 octahedral 16d (B) crystallographic positions [35]. Magnetite and maghemite can be represented with a single formula [38]: $\left(\mathrm{Fe}^{3+}\right)_{\mathrm{A}}\left[\left(\mathrm{Fe}^{2+}\right)_{1-3 \delta}\left(\mathrm{Fe}^{3+}\right)_{1+2 \delta} \square_{\delta}\right]_{\mathrm{B}} \mathrm{O}_{4}$, where $\square$ stands for vacancies and $0 \leq \delta \leq 1 / 3$. In pure magnetite $(\delta=0)$, all A sites are occupied by $\mathrm{Fe}^{3+}$ ions, while $\mathrm{B}$ sites are equally occupied with $\mathrm{Fe}^{2+}$ and $\mathrm{Fe}^{3+}$. In pure maghemite $(\delta=1 / 3)$, all $\mathrm{Fe}$ ions are in 3+ state, with tendency for regular arrangement at B sites (two occupied followed by one vacant site). Vacancies occur preferentially at octahedral sites [35], but they can also mix over octahedral and tetrahedral sites [39]. The degree of vacancy ordering in maghemite decreases with particle size, and it is believed that for NPs smaller than 20 nm vacancy ordering vanishes [27 and Refs. therein]. Magnetite and maghemite are both ferrimagnetic (the two uneven ferromagnetic sublattices $\mathrm{Fe}_{\mathrm{A}}$ and $\mathrm{Fe}_{\mathrm{B}}$ are antiferromagnetically aligned), with comparable saturation magnetizations $\left(\mathrm{M}_{\mathrm{S}}=90\right.$ $\mathrm{emu} / \mathrm{g}$ for magnetite; $\mathrm{M}_{\mathrm{S}}=83.5 \mathrm{emu} / \mathrm{g}$ for well ordered crystalline maghemite samples) and extraordinary high Curie temperatures $\left(\mathrm{T}_{\mathrm{C}}=858 \mathrm{~K}\right.$ magnetite; $\mathrm{T}_{\mathrm{C}}=790-893 \mathrm{~K}$ maghemite, depending on the degree of $\mathrm{C}-\mathrm{V}$ ordering) [35]. The important difference between magnetite and maghemite is in that maghemite is an insulator with energy gap $\mathrm{E}_{\mathrm{g}} \approx 2 \mathrm{eV}$, while magnetite is half-metal with much narrower $\mathrm{E}_{\mathrm{g}}=0.1-0.5 \mathrm{eV}$ (depending on the sample quality). Furthermore, bulk magnetite undergoes so-called Verwey order-disorder phase transition to the insulating state at temperatures $120-125$ 
$\mathrm{K}$ [35], accompanied with structural change from cubic to monoclinic lattice symmetry and various anomalies in the physical properties [40]. The decisive influence on this complex transformation is ascribed to charge and orbital ordering involved in the threesite distortions [41]. The exact structural parameters of the low temperature (LT) crystal structure, which is thought to have at least four inequivalent octahedral Fe sites [42], are extremely difficult to determine. Things are even more elusive when the sample size is in the nanometer range. According to [43] for NPs with the mean size $\sim 50 \mathrm{~nm}$ the Verwey temperature $\left(\mathrm{T}_{\mathrm{V}}\right)$ shifts down to $20 \mathrm{~K}$ and it can not be observed for smaller particles. According to some recent reports [44] the Verwey transition is weakly sizedependent in magnetite NPs larger than $20 \mathrm{~nm}$, slightly suppressed in NPs smaller than $20 \mathrm{~nm}$, and completely vanishes for NPs smaller than $6 \mathrm{~nm}$. These inconsistencies are often ascribed to the fact that final properties of magnetite NPs strongly depend also on structural order $[34,45]$.

Detailed characterization of magnetite NPs is therefore necessary in order to obtain accurate relationship between their electronic, magnetic and structural properties. In this paper magnetite NPs prepared by the EC method were studied by X-ray diffraction (XRD), X-ray absorption near edge structure (XANES), Extended X-ray absorption fine structure (EXAFS) and X-ray magnetic circular dichroism (XMCD). In that way a direct insight into the structure and electronic features of the Fe immediate surrounding (both inside NPs and at the surface) is obtained and effects of local structural and electronic modifications between the two characteristic temperatures ( $20 \mathrm{~K}$ and RT) were elucidated. The NPs stability in ambient conditions is monitored through 
XANES/EXAFS measurements performed on selected samples after long-term air exposure.

\section{Experiment}

The investigated magnetite NPs were produced in the electrochemical cell at temperatures $333 \mathrm{~K}$ and $361 \mathrm{~K}$ and current densities $\mathrm{J}=200$ and $1000 \mathrm{~mA} / \mathrm{dm}^{2}$ using the 0.04 normal $\mathrm{NaCl}$ solution in deionised water as electrolyte. Two rectangular steel plates $3 \mathrm{~cm}$ apart, were used as electrodes. The principle reactions taking place during

synthesis are: $\mathrm{Fe}^{3+}+3 \mathrm{OH}_{2} \leftrightarrow(\gamma$ and/or $\alpha)-\mathrm{FeOOH}+\mathrm{H}_{2} \mathrm{O}, 2 \mathrm{H}_{2} \mathrm{O}+4 \mathrm{H}^{+}+4 \mathrm{e}^{-}+\mathrm{O}_{2}$ (anode) and $\mathrm{H}_{2} \mathrm{O}+\mathrm{e}^{-} \leftrightarrow 1 / 2 \mathrm{H}_{2}+\mathrm{OH}^{-}$(cathode). The iron oxide, produced at the interface of electrodeelectrolyte according to the reaction $3(\gamma$ and/or $\alpha)-\mathrm{FeOOH}+1 / 2 \mathrm{H}_{2} \rightarrow \mathrm{Fe}_{3} \mathrm{O}_{4}+2 \mathrm{H}_{2} \mathrm{O}$, is deposited on the electrode in the form of nanopowder [32]. XRD measurements were performed on Siemens D5000 diffractometer with Ni filtered $\mathrm{Cu}-\mathrm{K}_{\alpha 1,2}$ radiation in Bragg-Brentano geometry in the range of angles $10^{\circ}<2 \theta<90^{\circ}$ using a step width $0.02^{0}$ and acquisition time 2 s/step. XAFS measurements at the Fe K-edge were performed on the C1 Beamline at Deutsches Elektronen-Synchrotron DESY (Hamburg, Germany). The nature of the EC synthesized NPs (variable shapes, morphologies and dimensions of grains) requires XAFS spectra to be collected in fluorescence yield (FY) mode, rather than in transmission. In order to monitor the X-ray fluorescence, the powders were pressed into 2-3 mm thick pellets. Data processing and analysis were performed using IFEFFIT [46] as implemented in ATHENA and ARHEMIS software packages [47], according to the standard procedure described elsewhere [48]. XAFS/XMCD measurements at the $\mathrm{Fe} \mathrm{L}_{2,3}$-edge were performed in total-electron yield (TEY) mode 
on Circular Polarization Beamline at Elettra Synchrotron Radiation Facility (Trieste, Italy). Circularly polarized absorption spectra were measured in the external magnetic field $\mathrm{B}=0.3 \mathrm{~T}$ applied perpendicular to the sample surface, with photon helicity $\rho^{+}$ (right-handed) and $\rho^{-}$(left-handed) reversed at each photon energy. The degree of circular polarization was $80 \%$ and the energy resolution $0.6 \mathrm{eV}$.

\section{Results and discussion}

The synthesis conditions of the investigated magnetite NPs are presented in Table 1. The same synthesis time ( $\mathrm{t}=60 \mathrm{~min})$ was applied to all samples (I-IV).

XRD diffractograms of samples I and II are presented in Fig. 1. Clearly visible noise originates from the $\mathrm{Fe} \mathrm{K}_{\alpha}$ fluorescence background. All diffraction peaks are indexed as magnetite (reference code: JCPDS 01-088-0315), with exception of the (110) reflection in Fig. 1b, which belongs to primitive cubic cell [35] and usually relates to maghemite with partially ordered vacancies [39]. According to the XRD results, samples I and II have the same lattice constant $(\mathrm{a}=8.366 \AA)$ which lies in-between the lattice constants of bulk maghemite ( $\mathrm{a}=8.334 \AA)$ and magnetite $(\mathrm{a}=8.396 \AA)$ [49]. The mean particle size $\sim 26 \mathrm{~nm}$, determined from the broadening of the (311) reflection is also the same for samples I and II. Detailed analysis of the particles size distribution of similar magnetite NPs can be found in $[29,32]$. The ratio of Fe ions in $2+/ 3+$ oxidation states, determined from the equation $[50] \mathrm{x}_{\mathrm{d}}=(\mathrm{a}-8.3424) / 0.1094=0.2$, also has an intermediate value between bulk maghemite $\left(\mathrm{x}_{\mathrm{d}}=0\right)$ and bulk magnetite $\left(\mathrm{x}_{\mathrm{d}}=0.5\right)$. 


\subsection{Fe K-edge XANES spectra}

The Fe K-edge XANES spectra of samples I-IV taken at $20 \mathrm{~K}$ and RT (with the insets showing the pre-edge regions enlarged) are presented in Fig. 2a and Fig. 2b, respectively. Fig. 2c shows the collection of corresponding absorption edge positions and Fig. $2 d$ the integrated pre-edge intensities. As it can be seen from Figs. $2 a$ and 2b, at both temperatures XANES spectra of samples I and III have less intense white lines and higher pre-edge peak intensities than the spectra of samples II and IV (see Fig. 2d). At the same time, the absorption edge in samples I and III is $0.4-0.5 \mathrm{eV}$ lower in energy (see Fig. 2c), which indicates that average Fe valence in samples I and III is smaller than in samples II and IV. In all samples the integrated pre-edge peak intensity is higher at LT than at RT (see Fig. 2d), most likely as a consequence of local structural distortions present in the LT phase [23,37], and higher in samples I and III than in samples II and IV. The pre-edge XANES region contains contributions originating from Fe in different oxidation states and different coordination environments [51]. The main contribution to the pre-edge peak intensity in magnetite arises from the $\mathrm{Fe}^{3+}$ in tetrahedral (A) coordination. The contributions originating from $\mathrm{Fe}^{3+}$ and $\mathrm{Fe}^{2+}$ in octahedral (B) coordination are much smaller since they are mainly caused by its departure from centrosymmetry [51]. To extract these three contributions the pre-edge region of the experimental XANES spectra is fitted to three Gaussian profiles of the same width $(1.2 \mathrm{eV})$. The baseline under the pre-edge is modeled with an arc-tangent function. The fitting procedure demonstrated on the XANES spectrum of sample I is shown in Fig. 3. The main component at $7113.0 \mathrm{eV}$ arises predominantly from tetrahedrally coordinated $\mathrm{Fe}^{3+}$, whereas the components at 7111.6 and $7114.4 \mathrm{eV}$ can be 
primarily ascribed to octahedrally coordinated $\mathrm{Fe}^{2+}$ and $\mathrm{Fe}^{3+}$, respectively (see Fig. 3). The intensities of the three pre-edge components in all investigated samples are shown in Fig. 4 (LT-open squares; RT-filled squares). Regardless of the trend observed for the total pre-edge peak intensity (see Fig. 2d), when going from $20 \mathrm{~K}$ to RT the intensity of $\mathrm{Fe}^{2+}(\mathrm{B})$ and $\mathrm{Fe}^{3+}(\mathrm{A})$ contributions decreases and the intensity of $\mathrm{Fe}^{3+}(\mathrm{B})$ contribution increases in all investigated samples (see Fig. 4). This temperature trend of cation distribution is characteristic for random spinel structure of magnetite in which distribution of $\mathrm{Fe}^{2+}$ ions runs over both tetrahedral and octahedral sites [52,53].

The presented XANES results clearly demonstrate non-stoichiometry of the investigated magnetite NPs, as first indicated by XRD results. The relative amount of the non-stoichiometric $\mathrm{Fe}_{3-\delta} \mathrm{O}_{4}$ oxide phase grown inside the NPs is influenced by preparation conditions, with current density being a decisive parameter. The stoichiometry of samples I and III prepared under smaller current density ( $\mathrm{J}=200$ $\left.\mathrm{mA} / \mathrm{dm}^{2}\right)$ is closer to bulk magnetite. Larger current density $\left(\mathrm{J}=1000 \mathrm{~mA} / \mathrm{dm}^{2}\right)$ has led to formation of NPs (samples II and IV) with structural and electronic properties which are more maghemite-alike. Plausible reason behind these observations could be that smaller current applied during the synthesis (with other parameters being the same, see Table 1) enables the NPs formation conditions to be closer to equilibrium. The ratio $\mathrm{Fe}^{3+} / \Sigma \mathrm{Fe}\left(\Sigma \mathrm{Fe}=\mathrm{Fe}^{2+}+\mathrm{Fe}^{3+}\right)$ determined from the XANES pre-edge fitting is smaller in samples I and III $(0.90 \pm 0.06)$ than in samples II and IV $(0.93 \pm 0.06)$, but still larger than that of bulk magnetite (0.67) [35]. These findings provide arguments in support of recent observations $[45,54]$ according to which nano-sized magnetite's structure can be 
regarded as a mixture of "structurally adapted" intermediate bulk magnetite and maghemite.

\subsection{Fe K-edge EXAFS spectra}

The Fe K-edge EXAFS spectra of samples I-IV taken at $20 \mathrm{~K}$ and RT are presented in Figs. 5a and 5b, and their Fourier transforms (FT) are shown in Figs. 5c and 5d, respectively. The first peak in Figs. 5c and 5d originates from two different oxygen coordination shells around $\mathrm{Fe}$ at $\mathrm{A}$ and $\mathrm{B}$ sites $\left(\mathrm{Fe}_{\mathrm{A}}-\mathrm{O}\right.$ and $\left.\mathrm{Fe}_{\mathrm{B}}-\mathrm{O}\right)$. The second peak contains contributions from the second coordination $\mathrm{Fe}$ atoms $\left(\mathrm{Fe}_{\mathrm{A}}-\mathrm{Fe}_{\mathrm{A}}, \mathrm{Fe}_{\mathrm{A}}-\mathrm{Fe}_{\mathrm{B}}\right.$ and $\left.\mathrm{Fe}_{\mathrm{B}}-\mathrm{Fe}_{\mathrm{B}}\right)$. In absence of peak splitting, which would facilitate discrimination between $\mathrm{A}$ and B sites, the FT-EXAFS spectra can be unambiguously ascribed neither to maghemite [55] nor to maghemite [56]. The position of the $\mathrm{Fe}-\mathrm{O}$ peak is weakly temperature-dependent and coincides in all investigated samples (see Figs. $5 \mathrm{c}$ and 5d), which indicates that the average $\mathrm{Fe}-\mathrm{O}$ distance does not vary substantially with stoichiometry and temperature. On the other side, the intensity of the Fe-Fe peak markedly decreases with temperature (see Figs. 5 c,d) and it is both sample- and temperature-dependent. Even though larger thermal disorder at RT is expected to suppress all FT-EXAFS amplitudes, this appears to be true only for Fe-Fe peak, while the intensity of $\mathrm{Fe}-\mathrm{O}$ peak remains nearly constant with temperature. The same temperature trend of $\mathrm{Fe}-\mathrm{O}$ and $\mathrm{Fe}-\mathrm{Fe}$ peaks intensities in FT-EXAFS spectra of magnetite [55] was explained in terms of nearly invariable local structure of $\mathrm{O}$ atoms in the first Fe-coordination above and below $\mathrm{T}_{\mathrm{V}}$. Changes of the $\mathrm{Fe}-\mathrm{Fe}$ peak were ascribed to the fact that the Verwey transition in magnetite is induced by the structural changes 
beyond the first coordination $\mathrm{Fe}-\mathrm{O}$ shell [55]. Stability of the first coordination $\mathrm{Fe}-\mathrm{O}$ shell and structural changes in the second coordination $\mathrm{Fe}-\mathrm{Fe}$ shell revealed in our EXAFS spectra could be a sign of the Verwey transition in the investigated NPs, regardless of the observed differences in their electronic structure.

\subsection{Fe $L_{2,3}$-edge XANES/XMCD spectra}

Results of XANES/XMCD measurements at the Fe $\mathrm{L}_{2,3}$-edge performed on samples I and II, are presented in Fig. 6. In addition to the information on Fe magnetic moments, $\mathrm{XMCD}$ technique is well suited to probe the extent of the surface oxidation due to high surface sensitivity of the employed TEY detection mode. The probing depth at the Fe $\mathrm{L}_{2,3}$-edge in iron oxides is typically $\sim 50 \AA$ [57] and hence the main contribution to absorption/dichroism signal arises from the atoms near the surface. The two main bands ( $\mathrm{L}_{3}$ and $\mathrm{L}_{2}$ ) appearing in the Fe $\mathrm{L}_{2,3}$-edge XANES spectra (see Fig. 6a) are separated by the spin-orbit coupling of the $2 p$ hole $\left(2 p_{3 / 2}\right.$ and $\left.2 p_{1 / 2}\right)$. The fine structure of the bands is determined by a complex interplay of atomic multiplets, ligand field splitting and the first coordination interatomic interactions for each of the three distinct electronic/magnetic Fe sites in magnetite [57].

Unlike the Fe $\mathrm{K}$-edge, no apparent difference is visible in the $\mathrm{Fe}_{2,3}-$ edge XANES spectra of samples I and II (see Fig. 6a), most likely due to the intrinsic limitations of the $\mathrm{Fe} \mathrm{L}_{2,3}$-egde XANES spectroscopy [45]. More explicit information can be extracted from the corresponding XMCD spectra, obtained by subtraction of the XANES spectra recorded in external magnetic field with right and left circularly polarized $\mathrm{X}$-rays. 
Three main features of the $\mathrm{L}_{3}$-band (see Fig. 6b) originate from $\mathrm{Fe}^{3+}(\mathrm{A}), \mathrm{Fe}^{3+}(\mathrm{B})$ and $\mathrm{Fe}^{2+}(\mathrm{B})[58]$, and the opposite sign in the XMCD signal reflects anti-parallel orientation of $\mathrm{Fe}(\mathrm{A})$ and $\mathrm{Fe}(\mathrm{B})$ spins. As can be seen in Fig. 6b, the XMCD spectra of samples I and II are considerably different. The intensities of the $\mathrm{Fe}^{3+}$ peaks at $\mathrm{A}$ and $\mathrm{B}$ sites are both much higher in sample II, which makes its XMCD spectrum to appear more maghemite-alike [59]. The XMCD spectrum of sample I is somewhere in-between bulk magnetite and maghemite [60], implying that its surface is oxidized to a lesser extent than the surface of sample II.

\subsection{Structural stability}

To elucidate how the long-term air exposure affects the phases originally formed in the EC synthesized NPs, samples I and II had been stored in ambient conditions and Fe Kedge XAFS measurements were repeated after two years. These measurement sets are denoted by asterix. The Fe K-edge XANES spectra of samples I* and II ${ }^{*}$ are presented in Fig. 7a and Fig. 7b, respectively, and the corresponding FT-EXAFS spectra are shown in insets. XANES/EXAFS spectra of samples I and II are also given for comparison. As can be seen from Figs. 7a and 7b, the long-term exposure to air has larger impact on sample I with initial structure closer to bulk magnetite. The characteristic XANES (pre-edges and white lines) and FT-EXAFS features are considerably different in samples I and $\mathrm{I}^{*}$, whereas in samples II and II ${ }^{*}$ only slight changes are noticeable (see Figs. $7 \mathrm{a}$ and $7 \mathrm{~b}$ ). The XANES pre-edge region was fitted using the same procedure described earlier and the collection of the integrated $\mathrm{Fe}^{2+}(\mathrm{B})$, $\mathrm{Fe}^{3+}(\mathrm{A})$ and $\mathrm{Fe}^{3+}(\mathrm{B})$ intensities for samples $\mathrm{I}^{*}$ and $\mathrm{II}^{*}$ are given in Figs. $7 \mathrm{c}$ and $7 \mathrm{~d}$, 
respectively. As it can be seen from Figs. 7c and 7d, decrease of the pre-edge intensity in samples I* and II ${ }^{*}$ is mainly caused by decrease of the $\mathrm{Fe}^{2+}(\mathrm{B})$ contribution. Together with a slight increase of the $\mathrm{Fe}^{3+}(\mathrm{B})$ contribution, this is what would be expected as far as oxidation of magnetite is concerned [35]. However, the fact that in both samples the $\mathrm{Fe}^{3+}(\mathrm{A})$ contribution increases (see Figs. $7 \mathrm{c}$ and $7 \mathrm{~d}$ ), implies that the long-term oxidation process in investigated NPs is accompanied with the $\mathrm{C}-\mathrm{V}$ reordering $[61,62]$. Changes of the integrated peak intensities are more pronounced in sample $\mathrm{I}^{*}$ and the relative increase of the $\mathrm{Fe}^{3+}$ contribution (at the expense of the $\mathrm{Fe}^{2+}$ contribution) is larger, indicating that unlike sample II ${ }^{*}$ the average Fe valence in sample $\mathrm{I}^{*}$ increases over time. Indeed, when compared to sample I, the absorption edge position of sample $\mathrm{I}^{*}$ is shifted $0.6-0.7 \mathrm{eV}$ to higher energy, while it remains nearly the same in samples II and II $^{*}$ (not shown). However, even with the observed shift the edge position in sample $\mathrm{I}^{*}$ is still lower than in sample $\mathrm{II}^{*}$, implying that sample $\mathrm{I}^{*}$ is less oxidized. On the other side, negligible changes of XANES/EXAFS spectra of the sample II* (see Fig. 7d) with structure initially closer to bulk maghemite imply that it is not entirely converted to maghemite even after being exposed to air for two years. It appears that the oxide shell formed relatively fast after its synthesis (as revealed by XMCD measurements) efficiently protects the core from further oxidation. The observed chemical composition difference between the core and the shell structure of investigated iron oxides NPs is in agreement with $[26,34,37,63]$.

Higher intensities of the FT-EXAFS peaks in sample I ${ }^{*}$ than in sample I (see inset of Fig. 7a) are most likely a result of particles agglomeration in the course of time, which relates to reduced disorder caused by under-coordinated surface atoms [45]. On the 
other side, FT-EXAFS spectra of samples II and II* are almost exactly alike (see inset of Fig. 7b), implying that over time not only the structure, but also the average particle size remains nearly the same, and that initially oxidized NPs are more stable in this respect, too. The stability of sample II-like NPs against both agglomeration and oxidation may have important practical consequences for their biomedical applications.

\section{Conclusions}

Detailed XRD, Fe $\mathrm{K}$ - and $\mathrm{L}_{2,3}$-edges XAFS and $\mathrm{L}_{2,3}$-edge XMCD studies of the electrochemically synthesized magnetite nanopowders were carried out in order to obtain direct insight into structure and electronic features of Fe immediate surrounding and to elucidate the effects of local structural and electronic modifications between the two characteristic temperatures ( $20 \mathrm{~K}$ and RT). Stability in ambient conditions was monitored by XANES/EXAFS measurements performed on selected samples after long-term exposure to air. All investigated nanopowders are produced as nonstoichiometric $\mathrm{Fe}_{3-\delta} \mathrm{O}_{4}$ oxide phases, with the lattice constant and the $\mathrm{Fe}^{2+} / \mathrm{Fe}^{3+}$ ratio both in-between the values for bulk maghemite and magnetite. The non stoichiometric $\mathrm{Fe}_{3-\delta} \mathrm{O}_{4}$ phase present inside the investigated samples has random spinel structure, and its relative amount is determined by preparation conditions. Characteristics of samples I and III prepared under smaller current density $\left(\mathrm{J}=200 \mathrm{~mA} / \mathrm{dm}^{2}\right)$ are closer to bulk magnetite. Larger current density $\left(\mathrm{J}=1000 \mathrm{~mA} / \mathrm{dm}^{2}\right)$ has led to formation of nanopowders (samples II and IV) whose structural and electronic properties are more maghemite-alike. Despite the observed structural and electronic differences, the first coordination $\mathrm{Fe}-\mathrm{O}$ shell preserves nearly invariable structure under the temperature 
change in all investigated samples. The local structural changes at $\mathrm{T}=20 \mathrm{~K}$ affect

primarily the second coordination shell around the Fe ions, thereby indicating existence of the Verwey transition. The extent to which investigated samples are influenced by the oxidation in ambient conditions is also found to highly depend on preparation conditions. The oxide shell formed in maghemite-like samples (II and IV) relatively fast after synthesis protects their core from further oxidation. The oxidation of magnetite-like samples (I and III) progresses more slowly and possibly extends more deeply into the core, and the long-term air exposure causes agglomeration of the particles.

\section{Acknowledgments}

The research leading to the presented results is supported by Serbian Ministry of Education, Science and Technological Development under the Grant III 45003. DESY (Hamburg, Germany) and Elettra (Trieste, Italy) are acknowledged for providing the beam time for XAFS/XMCD experiments.

\section{References}

[1] R.L. Rudnick (Ed.) Treatise on Geochemistry: The Crust, third vol., Elsevier, 2005.

[2] R.T. Merrill, M.W. McElhinny, P.L. McFadden, The Magnetic Field of the Earth: Paleomagnetism, the Core, and the Deep Mantle, Academic Press, San Diego, 1998.

[3] M.H. Carr, Water on Mars, Oxford University Press, New York, 1996. 
[4] P. Bahn, N. Franklin, M. Strecker (Eds.), Rock Art Studies - News of the World, third vol., Oxbow Books, Oxford, 2008.

[5] A.W. Batchelor, L.N. Lam, M. Chandrasekaran, Materials Degradation and Its Control by Surface Engineering, second ed., Imperial College Press, London, 2002.

[6] M. Hua, S. Zhang, B. Pan, W. Zhang, L. Lv, Q. Zhang, Heavy metal removal from water/wastewater by nanosized metal oxides: A review. J. Hazard. Mater. 211-212 (2012) 317-331.

[7] S.C.N. Tang and I.M.C. Lo, Magnetic nanoparticles: Essential factors for sustainable environmental applications, Water. Res. 47 (2013) 2613-2632.

[8] S. Mirshahghassemi, J.R. Lead, Oil Recovery from Water under Environmentally Relevant Conditions Using Magnetic Nanoparticles, Environ. Sci. Technol. 49 (2015) 11729-11736.

[9] M. Munoz, Z.M. de Pedro, J.A. Casas, J.J. Rodriguez, Preparation of magnetitebased catalysts and their application in heterogeneous Fenton oxidation - A review, Appl. Catal. B Environ. 176-177 (2015) 249-265.

[10] H.-M. Yang, K.-W. Lee, B.-K. Seo, J.-K. Moon, Copper FerrocyanideFunctionalized Magnetic Nanoparticles for the Selective Removal of Radioactive Cesium, J. Nanosci. Nanotechnol. 15 (2015) 1695-1699.

[11] M. Hosseinpour, S. Fatemi, S.J. Ahmadi, Catalytic cracking of petroleum vacuum residue in supercritical water media: Impact of $\alpha-\mathrm{Fe}_{2} \mathrm{O}_{3}$ in the form of free nanoparticles and silica-supported granules, Fuel 159 (2015) 538-549.

[12] C. Liu, F. Li, L.-P. Ma, H.-M. Cheng, Advanced Materials for Energy Storage, Adv. Mater. 22 (2010) E28-62. 
[13] Y. Chen, H. Xia, L. Lu, J. Xue, Synthesis of porous hollow $\mathrm{Fe}_{3} \mathrm{O}_{4}$ beads and their applications in lithium ion batteries, J. Mater. Chem. 22 (2012) 5006-5012.

[14] E. Mitchell, R.K. Gupta, K. Mensah-Darkwa, D. Kumar, K. Ramasamy, B.K. Gupta. P. Kahol, Facile synthesis and morphogenesis of superparamagnetic iron oxide nanoparticles for high-performance supercapacitor applications, New J. Chem. 38 (2014) 4344-4350.

[15] Q. Guo, X. Guo, K. Du, H. Ge, F. Wang, Superior high-rate capability of hierarchically structured flower-like magnetite-carbon-graphene composite for Li-ion anode, Int. J. Hydrogen Energy 40 (2015) 1846-1851.

[16] D. Ling, T. Hyeon, Chemical design of biocompatible iron oxide nanoparticles for medical applications, Small 9 (2013) 1450-1466.

[17] Q. Pankhurst, J. Connolly, Applications of magnetic nanoparticles in biomedicine. J. Phys. D.: Appl Phys 36 (2003) 167-181.

[18] C. Xu and S. Sun, New forms of superparamagnetic nanoparticles for biomedical applications, Adv. Drug Deliv. Rev. 65 (2013) 732-743.

[19] N.V. Long, C.M. Thi, Y. Yong, Y. Cao, H. Wu, M. Nogami, Synthesis and Characterization of Fe-Based Metal and Oxide Based Nanoparticles: Discoveries and Research Highlights of Potential Applications in Biology and Medicine, Recent Pat. Nanotechnol. 8 (2014) 52-61.

[20] T.H. Kim, E.Y. Jang, N.J. Lee, D.J. Choi, K.-J. Lee, J. Jang, J.Choi, S.H. Moon, J. Cheon, Nanoparticle assemblies as memristors, Nano Lett. 9 (2009) 2229-2233.

[21] T.S. Herng, W. Xiao, S.M. Poh, et al., Achieving a high magnetization in subnanostructured magnetite films by spin-flipping of tetrahedral $\mathrm{Fe}^{3+}$ cations, Nano Res. 8 (2015) 2935-2945. 
[22] J.-Y. Chen, T.-M. Wong, C.-W. Chang, C.-Y. Dong, Y.-F. Chen, Self-polarized spin-nanolasers, Nat. Nanotechnol. 9 (2014) 845-850.

[23] K. Yamauchi, T. Fukushima, S. Picozzi, Ferroelectricity in multiferroic magnetite $\mathrm{Fe}_{3} \mathrm{O}_{4}$ driven by noncentrosymmetric $\mathrm{Fe}^{2+} / \mathrm{Fe}^{3+}$ charge-ordering: First-principles study, Phys. Rev. B 79 (2009) 212404-4.

[24] J.-B. Moussy, From epitaxial growth of ferrite thin films to spin-polarized tunneling, J. Phys. D: Appl. Phys. 46 (2013) 143001-27.

[25] L.H. Fan, Y.L. Luo, Y.S. Chen, C.-H. Zhang, Q.-B. Wei, Preparation and characterization of $\mathrm{Fe}_{3} \mathrm{O}_{4}$ magnetic composite microspheres covered by a $\mathrm{P}(\mathrm{MAH}-$ co-MAA) copolymer, J. Nanoparticle Res. 11 (2009) 449-458

[26] R. Frison, G. Cernuto, A. Cervellino, O. Zaharko, G.M. Colonna, A. Guagliardi, N. Masciocchi, Magnetite-maghemite nanoparticles in the 5-15 $\mathrm{nm}$ range: Correlating the core-shell composition and the surface structure to the magnetic properties. A total scattering study, Chem. Mater. 25 (2013) 4820-4827.

[27] A.S. Teja and P.-Y. Koh, Synthesis, properties, and applications of magnetic iron oxide nanoparticles, Prog. Cryst. Growth Charact. Mater. 55 (2009) 22-45.

[28] D. Stanicki, L. Vander Elst, R.N. Muller, S. Laurent, Synthesis and processing of magnetic nanoparticles, Curr. Opin. Chem. Eng. 8 (2015) 7-14.

[29] LJ. Vulićević, N. Ivanović, N. Popović, M. Novaković, M. Popović, M. Mitrić, V. Andrić, D. Babć, Investigation of properties of electrochemically synthesized iron oxide nano-powders, Journal of Microscopy, 232 (2008) 629-633.

[30] L. Cabrera, S. Gutierrez, N. Menendez, M.P. Morales, P. Herrasti, Magnetite nanoparticles: Electrochemical synthesis and characterization, Electrochim. Acta 53 (2008) 3436-3441. 
[31] F. Fajaroh, H. Setyawan, W. Widiyastuti, S. Winardi, Synthesis of magnetite nanoparticles by surfactant-free electrochemical method in an aqueous system, Adv. Powder Technol. 23 (2012) 328-333.

[32] D. Mamula-Tartalja, LJ. Vulićević, I. Radisavljević, M. Mitrić, V. Andrić, B. Kuzmanović, M. Medić, N. Ivanović, Effects of manufacturing conditions and heating on properties of electrochemically produced magnetite nano-powders, Ceram. Int. 40 (2014) 3517-3525.

[33] C. Boyer, M.R. Whittaker, V. Bulmus, J. Liu, T.P. Davis, The design and utility of polymer-stabilized iron-oxide nanoparticles for nanomedicine applications, Asia Mater. 2 (2010) 23-30.

[34] A. Demortière, P. Panissod, B.P. Pichon, G. Pourroy, D. Guillon, B. Donnio, S. Bégin-Colin, Size-dependent properties of magnetic iron oxide nanocrystals, Nanoscale 3 (2011) 225-232.

[35] R.M. Cornell and U. Schwertmann, The Iron Oxides: Structure, Properties, Reactions, Occurrences and Uses, second ed., Wiley, New York, 2003.

[36] J. Tang, M. Myers, K.A. Bosnick, L.E. Brus, Magnetite $\mathrm{Fe}_{3} \mathrm{O}_{4}$ Nanocrystals: Spectroscopic Observation of Aqueous Oxidation Kinetics, J. Phys. Chem. B 107 (2003) 7501-7506.

[37] R. Bliem, E. McDermott, P. Ferstl, Subsurface cation vacancy stabilization of the magnetite (001) surface, Science 346 (2014)1215-8.

[38] C.I. Pearce, C.M.B. Henderson, R.A.D. Pattick, G. van der Laan, D.J. Vaughan, Direct determination of cation site occupancies in natural ferrite spinels by $\mathrm{L}_{2,3} \mathrm{X}-$ ray absorption spectroscopy and $\mathrm{x}$-ray magnetic circular dichroism, Am. Mineral. 92 (2006) 880-893. 
[39] C.B. de Boer and M.J. Dekkers, Unusual thermomagnetic behaviuor of haematites: neoformation of a highly magnetic spinel phase on heating in air, Geophys. J. Int. 144 (2001) 481-494.

[40] F. Walz, The Verwey transition - a topical review, J. Phys. Condens. Matter. 14 (2002) R285-340.

[41] M.S. Senn, J.P. Wright, J.P. Attfield, Charge order and three-site distortions in the Verwey structure of magnetite, Nature 481 (2011) 173-176.

[42] M. Iizumi, T.F. Koetzle, G. Shirane, S. Chikazumi, M. Matsui, S. Todo, Structure of magnetite $\left(\mathrm{Fe}_{3} \mathrm{O}_{4}\right)$ below the Verwey transition temperature, Acta Cryst. B 38 (1982) 2121-2133.

[43] G.F. Goya, T.S. Berquo, F.C. Fonseca, M.P. Morales, Static and Dynamic Magnetic Properties of Spherical Magnetite Nanoparticles. J. Appl. Phys. 94 (2003) $3520-3528$.

[44] J. Lee, S.G. Kwon, J.-G. Park, T. Hyeon, Size Dependence of Metal-Insulator Transition in Stoichiometric $\mathrm{Fe}_{3} \mathrm{O}_{4}$ Nanocrystals, Nano Lett. 15 (2015) 4337-4342.

[45] A. Kuzmin and J. Chaboy, EXAFS and XANES analysis of oxides at the nanoscale, IUCrJ 1 (2014) 571-589.

[46] M. Newville, IFEFFIT: interactive XAFS analysis and FEFF fitting, J. Synchrotron Radiat. 8 (2001) 322-324.

[47] B. Ravel and M. Newville, ATHENA, ARTEMIS, HEPHAESTUS: data analysis for X-ray absorption spectroscopy using IFEFFIT, J. Synchrotron Radiat. 12 (2005) 537-541. 
[48] I. Radisavljević, N. Ivanović, N. Novaković, N. Romčević, M. Mitrić, V. Andrić, H.-E. Mahnke, Structural aspects of changes induced in PbTe by doping with Mn, In and Ga, J. Mater. Sci. 48 (2013) 8084-8100.

[49] B.A. Wechsler, D.H. Lindsley, C.T. Prewitt, Am. Mineral. 69 (1984) 754-770.

[50] C.A. Gorsky, M.M. Scherer, Determination of nanoparticulate magnetite stoichiometry by Mössbauer spectroscopy, acidic dissolution, and powder X-ray diffraction: A critical review, Am. Mineral. 95 (2010) 1017-1026.

[51] M. Wilke, F. Farges, P.E. Petit, G.E. Brown Jr, F. Martin, Oxidation state and coordination of Fe in minerals: An Fe K-XANES spectroscopic study, Am. Mineral. 86 (2001) 714-730.

[52] C.C. Wu and T.O. Mason, Thermopower Measurement of Cation Distribution in Magnetite, J. Am. Chem. Soc. 64 (1981) 520-522.

[53] T. Mathews and K.T. Jacob, Seebeck coefficient of magnetite: a reinterpretation invoking Jahn-Teller entropy, Solid State Commun. 84 (1992) 975-978.

[54] C. Piquer, M.A. Laguna-Marco, A.G. Roca, R. Boada, C. Guglieri, J. Chaboy, Fe $\mathrm{K}$-edge $\mathrm{X}$-ray absorption spectroscopy study of nanosized nominal magnetite, J. Phys. Chem. C 118 (2014) 1332-1346.

[55] G. Subías, J. García, J. Blasco, EXAFS spectroscopic analysis of the Verwey transition in $\mathrm{Fe}_{3} \mathrm{O}_{4}$, Phys. Rev. B 71 (2005) 155103-9.

[56] A. Corrias, G. Ennas, G. Mountjoy, G. Paschina, An X-ray absorption spectroscopy study of the $\mathrm{Fe} \mathrm{K}$ edge in nanosized maghemite and in $\mathrm{Fe}_{2} \mathrm{O}_{3}-\mathrm{SiO}_{2}$ nanocomposites, Phys. Chem. Chem. Phys. 2 (2000) 1045-1050. 
[57] S. Gota, M. Gautier-Soyer, M. Sacchi, Fe 2p absorption in magnetic oxides: Quantifying angular-dependent saturation effects, Phys. Rev. B 62 (2000) 41874190.

[58] R. Pattrik, G. van der Laan, M. Henderson, P. Kuiper, E. Dudzik, D. Vaughan, Cation site occupancy in spinel ferrites studied by X-ray magnetic circular dichroism: developing a method for mineralogists, Eur. J. Mineral. 14 (2002) $1095-1102$.

[59] S. Brice-Profeta, M.-A. Arrio, E. Tronc, N. Menguy, I. Letard, C. Cartier dit Moulin, M. Noguès, C. Chanéac, J. -P. Jolivet, Ph. Sainctavit, Magnetic order in $\gamma-$ $\mathrm{Fe}_{2} \mathrm{O}_{3}$ nanoparticles: a XMCD study, J. Magn. Magn. Mat. 288 (2005) 354-365.

[60] P. Kuiper, B.G. Searle, L.-C. Duda, R.M. Wolf, P.J. van der Zaag, Fe L L 2,3 linear and circular magnetic dichroism of $\mathrm{Fe}_{3} \mathrm{O}_{4}$, J. Electron. Spectrosc. 86 (1997) 107113.

[61] J.-H. Park, J.W. Allen, P. Metcalf, C.T. Chen, Single-particle gap above the Verwey transition in $\mathrm{Fe}_{3} \mathrm{O}_{4}$, Phys. Rev. B 55 (1997) 12813-12817.

[62] M. Imada, A. Fujimori, Y. Tokura, Metal-insulator transitions, Rev. Mod. Phys. 70 (1998) 1039-1263.

[63] J. Santoyo Salazar, L. Perez, O. de Abril, L. Truong Phuoc, D. Ihiawakrim, M. Vazquez, J.-M. Greneche, S. Begin-Colin, G. Pourroy, Magnetic Iron Oxide Nanoparticles in 10-40 nm Range: Composition in Terms of Magnetite/Maghemite Ratio and Effect on the Magnetic Properties, Chem. Mater. 23 (2011) 1379-1386. 
Table 1. The synthesis conditions of the investigated magnetite NPs (samples I-IV).

\begin{tabular}{lll}
\hline Sample & $\mathrm{J}\left(\mathrm{mA} / \mathrm{dm}^{2}\right)$ & $\mathrm{T}(\mathrm{K})$ \\
\hline $\mathrm{I}$ & 200 & 333 \\
II & 1000 & 333 \\
III & 200 & 361 \\
IV & 1000 & 361 \\
\hline
\end{tabular}




\section{Figure captions}

Fig. 1. XRD diffractograms of the $\mathrm{Fe}_{3} \mathrm{O}_{4}$ samples I (a) and II (b).

Fig. 2. (a) The Fe K-edge XANES spectra of samples I-IV taken at $20 \mathrm{~K}$ (a) and RT (b) with the insets showing the pre-edge region enlarged. Collection of the absorption edge positions (c) and integrated pre-edge peak intensities (d) of samples I-IV (open squares-20 K, filled squares-RT).

Fig. 3. Fit of the Fe K-edge XANES pre-edge region of sample I (taken at $20 \mathrm{~K}$ ) using three Gaussian profiles for the $\mathrm{Fe}^{2+}(\mathrm{B}), \mathrm{Fe}^{3+}(\mathrm{A})$ and $\mathrm{Fe}^{3+}(\mathrm{B})$ contributions. The background was modeled by an arc-tangent function.

Fig.4. Positions and integrated intensities of the pre-edge contributions corresponding to $\mathrm{Fe}^{2+}(\mathrm{B}), \mathrm{Fe}^{3+}(\mathrm{A})$ and $\mathrm{Fe}^{3+}(\mathrm{B})$ for samples $\mathrm{I}-\mathrm{IV}$ at $20 \mathrm{~K}$ (open squares) and $\mathrm{RT}$ (filled squares).

Fig. 5. The Fe K-edge EXAFS spectra $(a, b)$ and their Fourier transforms $(c, d)$ of samples I-IV taken at $20 \mathrm{~K}$ and $\mathrm{RT}$, respectively.

Fig. 6. The Fe $\mathrm{L}_{2,3}$-edge XANES (a) and XMCD spectra (b) of samples I and II.

Fig. 7. The Fe K-edge XANES spectra of samples $I^{*}$ (a) and II $^{*}$ (b) taken at RT, with the Fourier transforms of the corresponding EXAFS spectra shown in insets.

Comparison of the positions and the integrated intensities of the three pre-edge components corresponding to $\mathrm{Fe}^{2+}(\mathrm{B}), \mathrm{Fe}^{3+}(\mathrm{A})$ and $\mathrm{Fe}^{3+}(\mathrm{B})$ obtained for samples I and $I^{*}(c)$ and samples II and II* (d) at RT. 


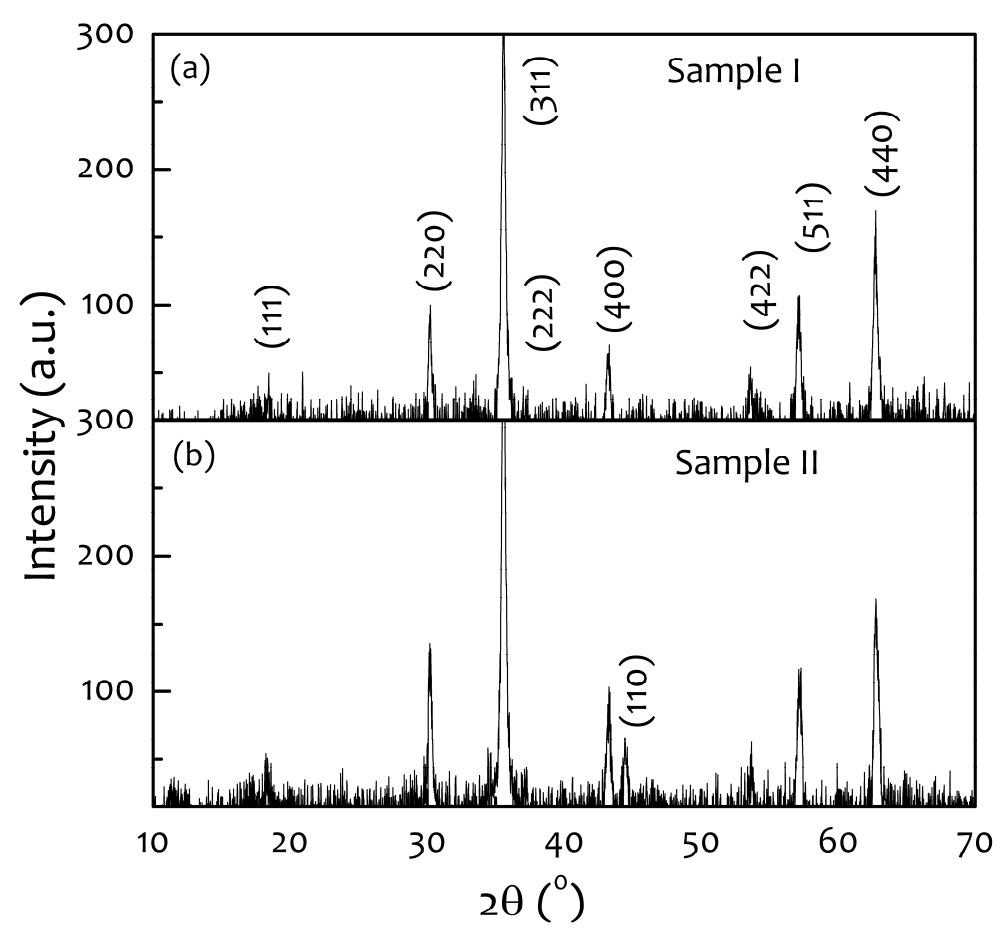

Figure 1.


Figure 2. 


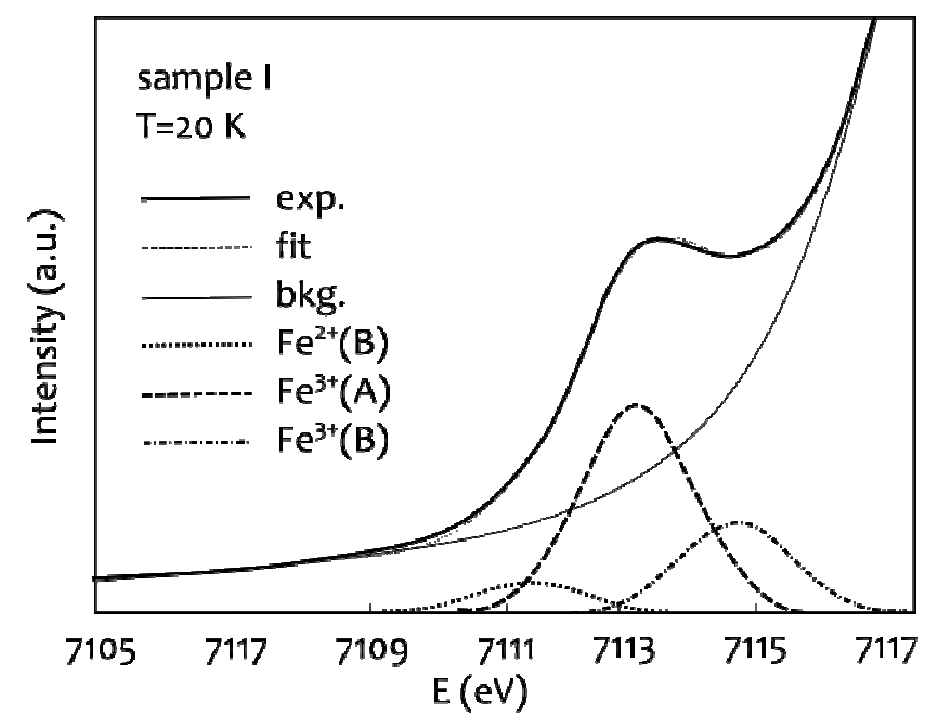

Figure 3.

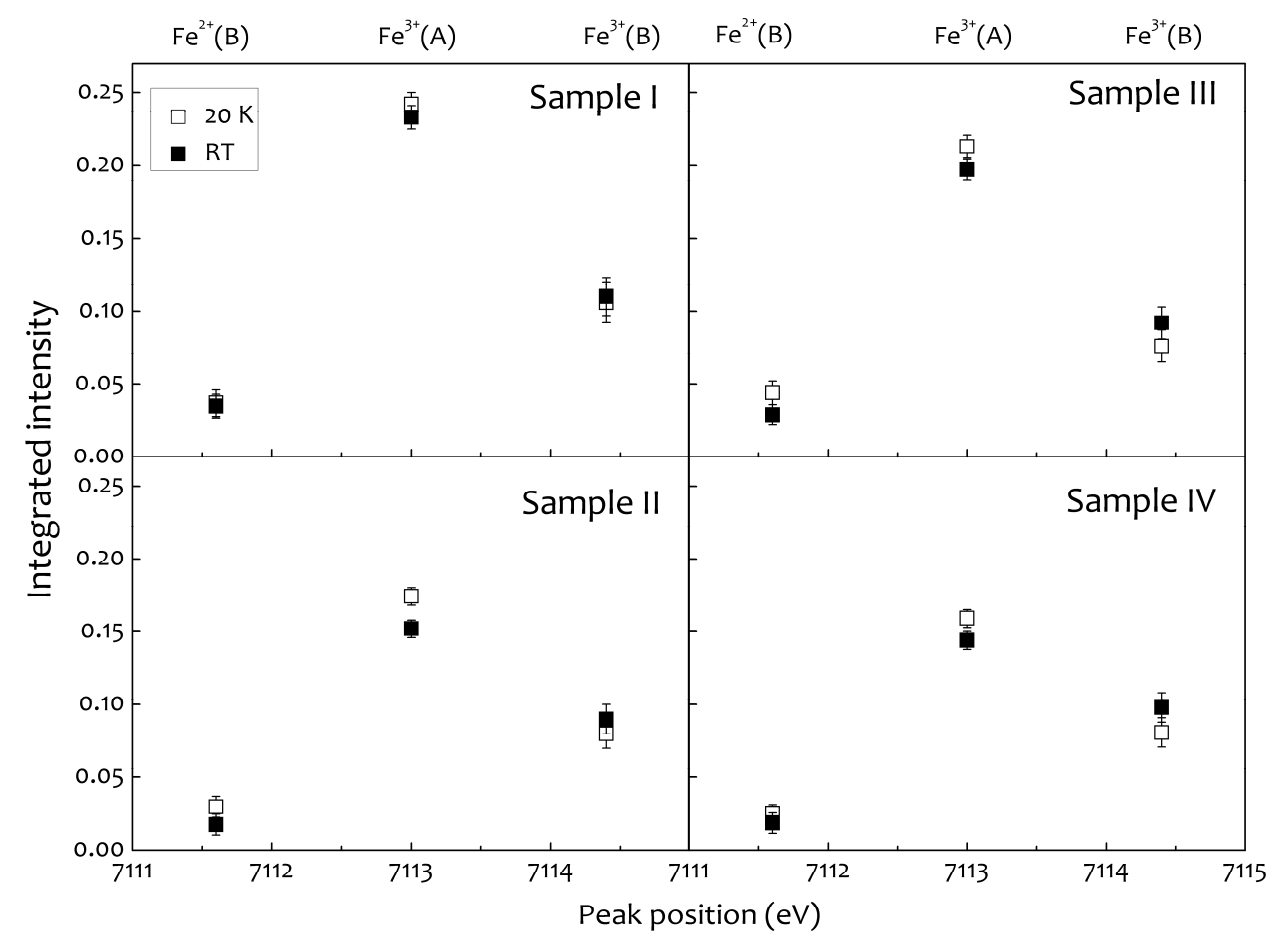

Figure 4. 

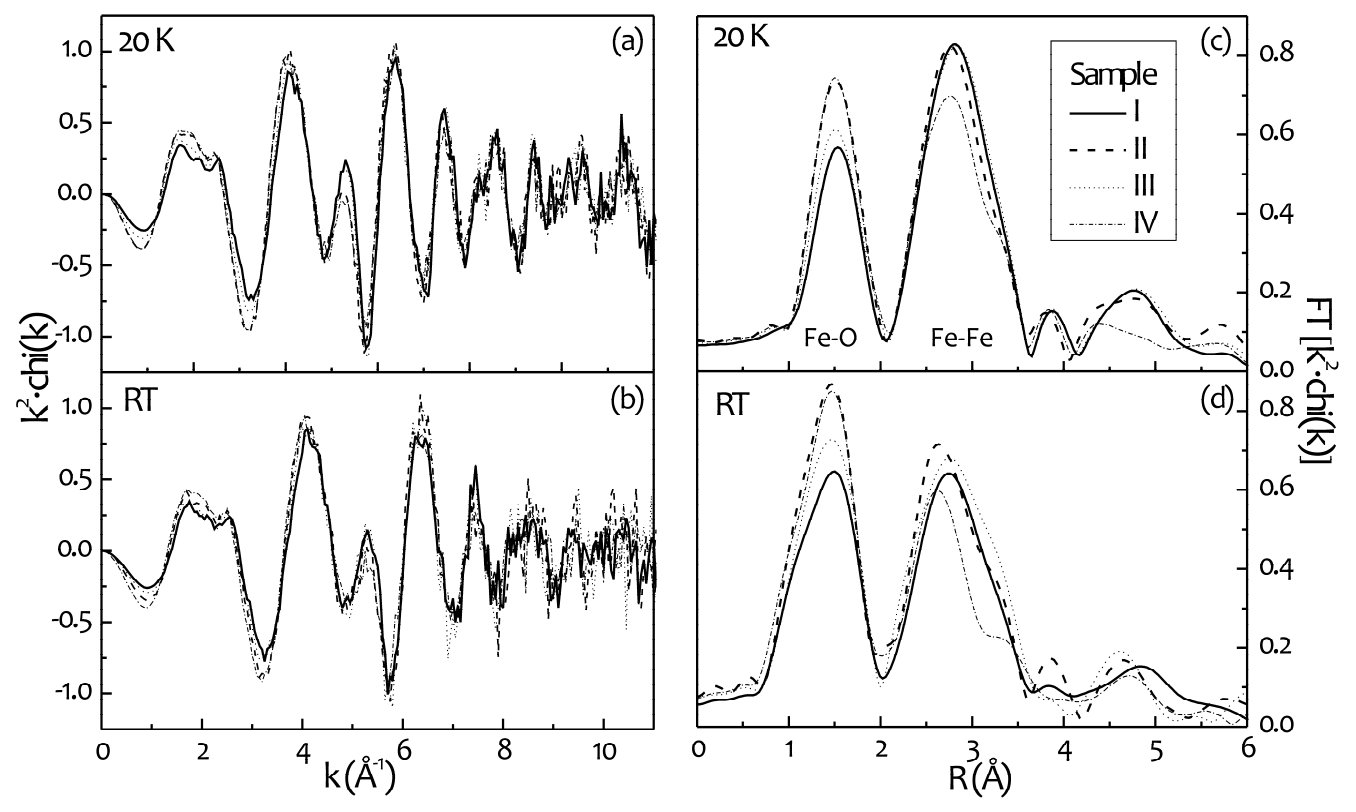

Figure 5. 


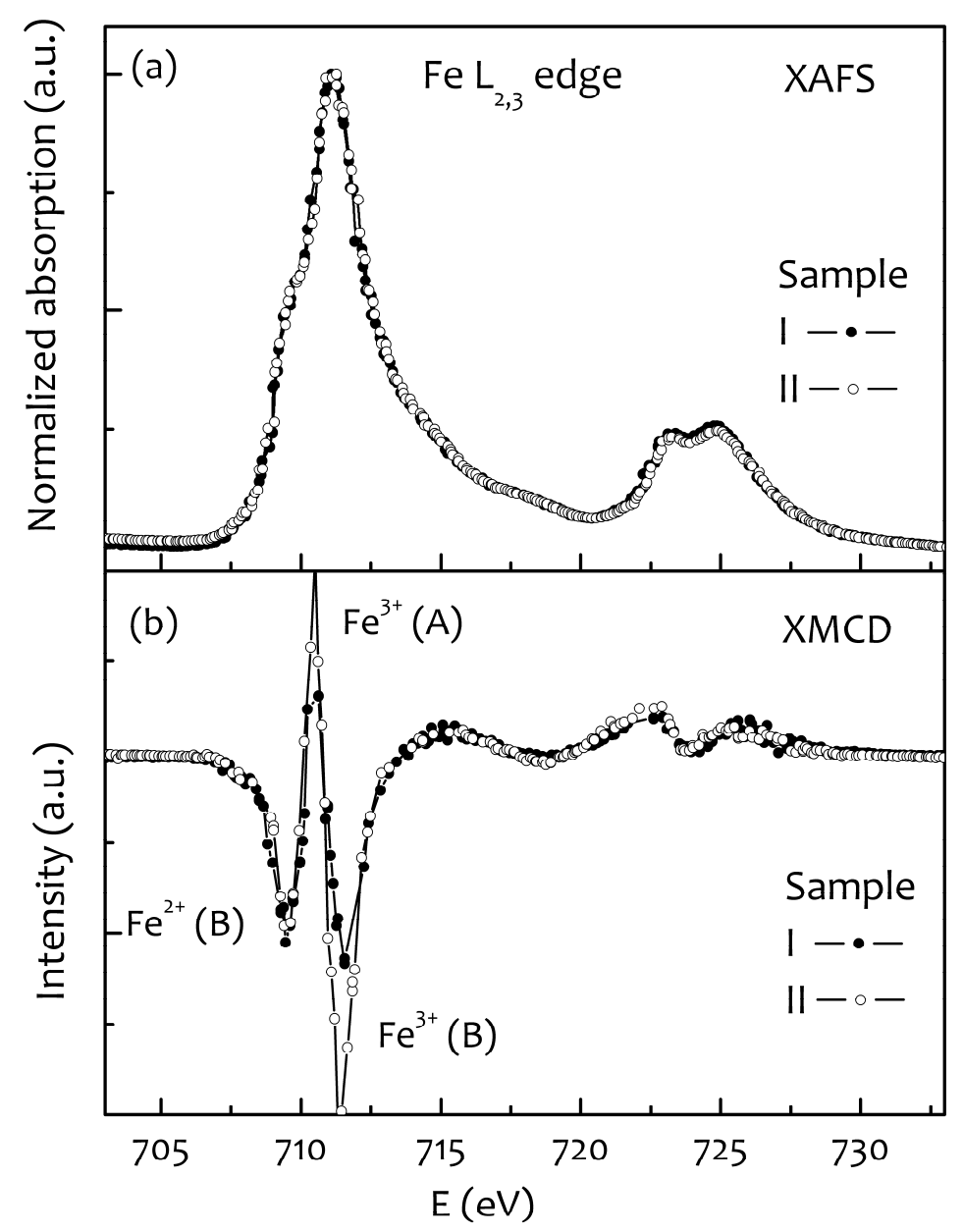

Figure 6. 

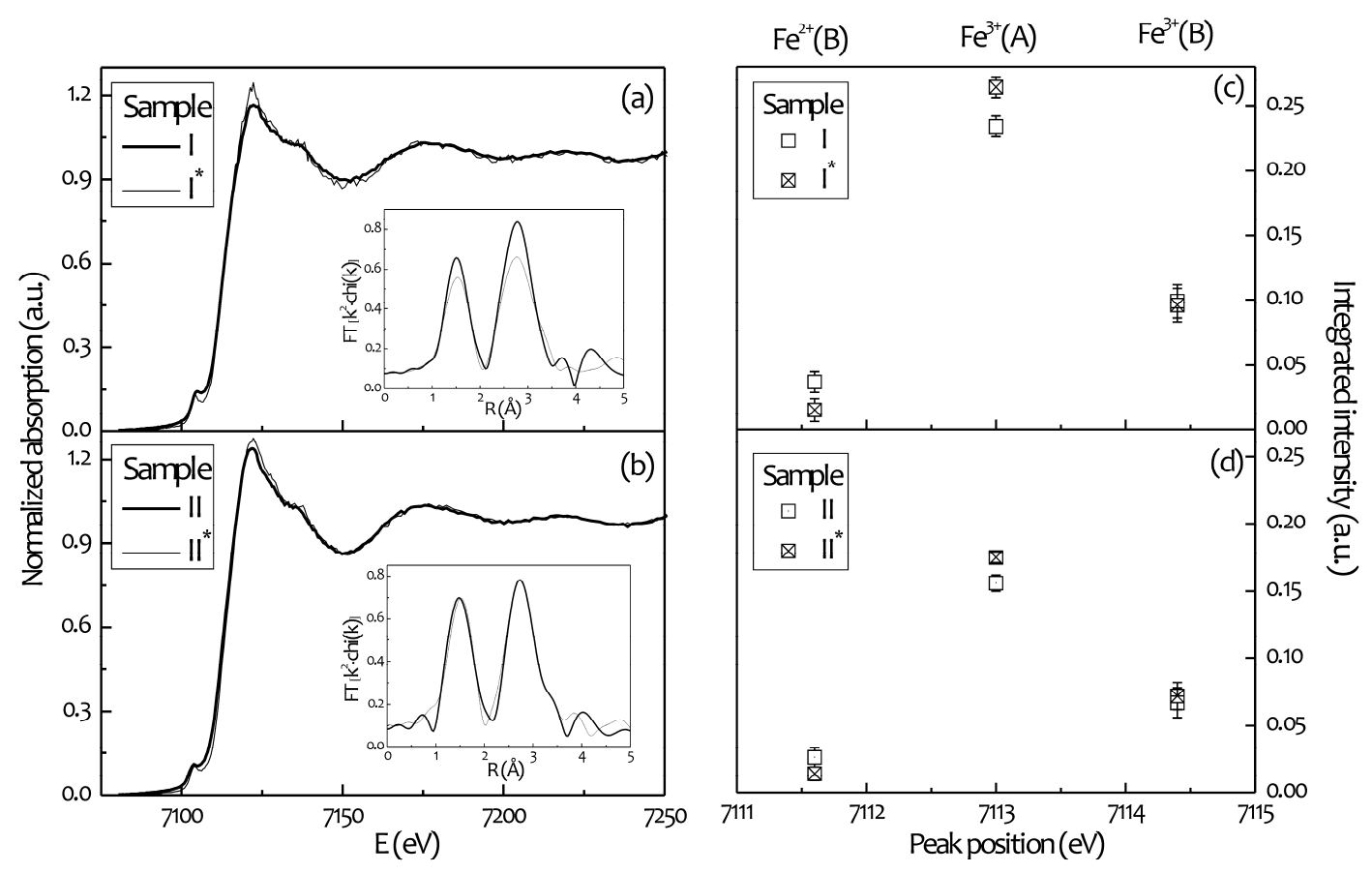

Figure 7. 